\title{
EXPERIENCIAS EN LA VIDA UNIVERSITARIA DE ESTUDIANTES DE PRIMEROS PROMEDIOS DE ADMISIÓN
}

\author{
Vivian María Pacheco Urbina
}

Recibido 03-IX-2002

Resumen: Con la finalidad de analizar los factores que intervienen en la excelencia académica de los estudiantes de primeros promedios de admisión de la Universidad de Costa Rica, se desarrolla una investigación etnográfica que utiliza la metodología cualitativa; la información se obtiene de las entrevistas en profundidad que se realizan a través de la construcción de las historias de vida de los estudiantes participantes. Asimismo, se aplica la observación directa y la recopilación de datos de fuentes documentales.

Este artículo presenta las vivencias, percepciones y opiniones de los estudiantes en la etapa de estudios universitarios, a partir de su experiencia de vida en la prueba de aptitud académica. La información que se presenta constituye en sí misma, una fuente de ideas para la reflexión del quehacer de la Universidad de Costa Rica, con relación a los estudiantes talentosos que ingresan con altas expectativas de desarrollo personal y profesional a nuestro sistema de estudios universitarios.

Palabras claves: Historias de Vida, Experiencias Universitarias.
Aceptado 12-XI-2002

\section{Introducción}

Las dos perspectivas epistemológicas principales que prevalecen en las ciencias sociales son la positivista y la fenomenológica.

La positivista busca los hechos o causas de los fenómenos sociales con independencia de los estados subjetivos de los individuos.

El fenomenólogo plantea el entender los fenómenos sociales desde la propia perspectiva del actor; busca comprensión por medio de la metodología cualitativa, a través de técnicas como la observación participante, la entrevista en profundidad y otros, que generan datos descriptivos. Lucha por lo que Max Weber (1968) denomina "verstehen", esto es, comprensión en un nivel personal de los motivos y creencias que están detrás de las acciones de la gente.

La perspectiva fenomenológica guía la presente investigación, que produce datos descriptivos por medio del método de las entrevistas en profundidad, del tipo de historias de vida, que permite obtener información de las propias palabras de las personas, habladas o escritas y de la conducta observable.

La historia de vida presenta la visión de su vida que tiene la persona, en sus propias palabras, en gran medida como una autobiografía en común (Taylor y 
Bogdan, 1986). Estas permiten obtener información mediante el intercambio verbal, registrado entre dos individuos, el que pregunta y el que responde. En el presente estudio, estos papeles los desempeñan la investigadora y cada uno de los estudiantes y las estudiantes participantes.

La historia de vida aporta una recopilación de las descripciones de los acontecimientos y experiencias importantes en la vida de los estudiantes y las estudiantes, en sus propias palabras, que tienen relación con el desarrollo de su talento cognitivo, aptitudes y habilidades. Las historias de vida de los informantes permitirán tener una visión integral de:

- Las relaciones, vivencias, expectativas del estudiante en el contexto sociocultural universitario.

- Sus logros y características en la vida del estudiante en la etapa universitaria.

- Valoración y criterio de la relación con el profesor de la universidad.

- Las características de su personalidad que los identifican con el desarrollo de sus potencialidades.

- $\quad$ Actitudes personales ante el examen de admisión de la Universidad de Costa Rica.

- $\quad$ Experiencias personales, vivencias estudiantiles y estímulos en su trayectoria como estudiante en la Universidad de Costa Rica.

La investigación procura recolectar la información de las historias de vida, que tenga mayor relación y significado con los factores que influyen en la excelencia académica, que obtienen los estudiantes de primeros promedios de admisión de la Universidad de Costa Rica.
Las entrevistas cualitativas en profundidad, en el tipo de historias de vida, permiten el aprendizaje sobre lo que es importante en la mente de los informantes: sus significados, perspectivas y definiciones: el modo en que ellos ven, clasifican y experimentan el mundo (Taylor y Bogdan, 1986). La investigadora establece y mantiene una relación recíproca con los estudiantes participantes en el estudio, basada en la confianza y en la que se registran con certeza las palabras, el lenguaje, los motivos de los informantes, que permitan a posteriori una explicación de su conducta, sus potencialidades, sus aptitudes y sus habilidades.

Se selecciona un grupo de informantes integrado por ocho estudiantes para la construcción de las historias de vida que obtuvieron el primero, el segundo o el tercer promedio de admisión en la Universidad de Costa Rica, en los años de 1991, 1992 y 1993 para establecer las experiencias de vida en el desarrollo de la carrera universitaria y de 1995, para determinar la percepción del estudiante de su ingreso a los estudios superiores.

El grupo de estudiantes se identifica con nombres supuestos: Marcos, Carolina, Daniel, Melissa, Manuel, Diana, Adrián y Paola. Esto se realiza para mantener la confidencialidad de la información suministrada por cada uno de los participantes en la investigación.

\section{Vivencias de estudiantes de primeros promedios de admisión en la etapa universitaria}

\section{Categorías establecidas para el análisis de la información}

Las historias de vida de los estudiantes participantes aportaron narraciones, experiencias, manifestaciones y percepciones individuales muy valiosas, de las que se obtiene información; la cual se 
organiza en cuatro categorías principales para establecer los factores determinantes de la excelencia académica, como estudiantes de primeros promedios de admisión de la Universidad de Costa Rica.

Las categorías están estructuradas para dar respuesta a los objetivos de la investigación; éstas se indican a continuación.

\section{Primera categoría:}

Forma como perciben los estudiantes participantes los elementos que ofrece el núcleo y el contexto socio-cultural para que se desarrolle el talento cognitivo, las aptitudes y habilidades en el individuo.

\section{Segunda categoría:}

Logros y características en la vida de los estudiantes en las etapas escolar, colegial y universitaria.

Tercera categoría:

Forma como los estudiantes perciben las cualidades de los administradores educativos que fomentan el desarrollo del potencial del individuo.

Cuarta categoría:

Principales características de la personalidad de los estudiantes participantes que influyen en sus logros académicos.

De acuerdo con los postulados de la metodología cualitativa, no se pretende generalizar los resultados; lo que se busca es un acercamiento directo con el informante que permita extraer de sus narraciones, manifestaciones y perspectivas, sus vivencias personales como estudiante de excelencia académica.

Los principales resultados obtenidos se ordenan de acuerdo con las cuatro categorías establecidas. Se incluyen, en todo el artículo, intervenciones textuales de los informantes que permiten enriquecer la investigación con elementos de una fuente primaria: la existencia del ser humano. Debido al volumen de información que se obtiene en esta investigación, en este artículo se presenta la segunda categoría: "Logros y características en la vida de los estudiantes en la etapa universitaria".

Se organiza la información en las subcategorías pertinentes a las vivencias del estudiante en sus años de estudios universitarios:

- $\quad$ ¿Cómo se siente el informante durante la realización de la prueba de aptitud académica?

- $\quad$ Actitud del estudiante y de su familia ante los primeros promedios de admisión.

- $\quad$ ¿Qué es lo que más valoran al obtener los mejores promedios de admisión?

- $\quad$ Experiencias sobre el ingreso a la U.C.R.

- Vivencias del informante en sus años de estudios universitarios.

- Las relaciones con los profesores y valoración del desempeño académico.

Los informantes analizan una serie de aspectos personales, familiares y de preparación e información para la prueba de aptitud académica. A su vez, estos aspectos denotan una serie de elementos externos a la U.C.R., que son parte de la motivación del estudiante para su ingreso a este centro de estudios superiores, lo mismo que de las repercusiones que tiene el resultado de esta prueba en el estudiante y en su núcleo familiar.

De acuerdo con la narración de los informantes Manuel, Adrián y Paola, la preparación que reciben de parte de los centros educativos para realizar la prueba 
de aptitud académica (P.A.A.) es mínima, y en la mayoría de los casos se reduce a la información general que suministra la U.C.R. a los colegios. Así lo manifiestan los informantes Manuel, Adrián y Paola:

Para el examen de admisión, no recibimos preparación por parte del colegio, sino que asistí en Tacares a un curso de una mañana de preparación para realizar el examen... Antes de hacer el examen de admisión, no tenía idea de cómo sería; la preocupación era saber como hacía para viajar a la Universidad y venir solo, ya que muchos de los compañeros iban para universidades privadas. No me llamaba la atención la universidad, debido a que tenía que dejar el colegio... No hice el examen de admisión del Tecnológico... Nunca pensé que iba a perder el examen de admisión de la U.C.R., esto hacía que no me preocupara. Lo importante era hacerlo, uno pensaba que por ganar el examen, ya tenía la oportunidad de ingresar a la U, sentía fácil el ingreso a la universidad. Nadie de la U.C.R. llegó a darnos charlas al colegio, fue el Orientador que nos explicó el proceso de admisión y nos dio fichas de información. No sabía que existiera la carrera de Tecnología de Alimentos, sólo sabía que existía Odontología. (Manuel).

Realizo el examen del Tecnológico y el de la U.C.R.; el primero lo realizo como práctica para el de la U... Para realizar el examen de la U.C.R., nos dan unos folletos de práctica de cómo era. Al hacer el examen, tengo la idea concreta de estudiar medicina, siento mucha seguridad al hacerlo. No recibí ninguna preparación para hacer el examen, hice la práctica que indica el folleto, la cual realicé un mes y medio antes del examen; nos llevan a una feria vocacional en FERCORI y nos dan información sobre universidades privadas, me gusta la UACA para Medicina, pero porque un amigo estudia ahí, ya que mi aspiración de primera opción es quedarme en la U.C.R. (Adrián).

Hago primero el examen del TEC, no lo siento difícil, sólo en la parte verbal sí. La misma temática. Al terminar el examen lo sentí entretenido, no difícil. No tuve tiempo de prepararme para el examen de la U.C.R., el día anterior tuve examen de cálculo, quería estar descansado, por lo que casi no estudié. Me acosté temprano y no hice práctica para el examen, porque estaba cansado... Sabiendo que era algo que tenía que hacer y tenía que dar mi máximo esfuerzo y concentrarme bien (Paola).

El ingreso a la Universidad genera una serie de expectativas en los informantes, según las características sociales y económicas de cada familia y muchas veces, según las aspiraciones de los padres en cuanto a la elección de la carrera que haga el hijo o la hija.

La realización de la P.A.A. de la Universidad de Costa Rica y la obtención de un puntaje que permita el ingreso a la carrera seleccionada, constituyen una meta que en los estudiantes de undécimo año despierta interés y motivación.

Destaca en los ocho informantes el propósito de obtener el mejor rendimiento en la P.A.A., aunque no el máximo puntaje, para satisfacción personal y familiar.

La P.A.A. es una experiencia particular que determina el ingreso del estudiante a la U.C.R., por lo cual en algunos de los informantes genera nerviosismo y preocupación; por el contrario, otros la asumen con tranquilidad. Así lo indican en su narración.

El día anterior al examen, voy al colegio y en la tarde leo lectura recreativa y ojeo la práctica realizada. Estaba tranquila... Veo a mi novio esa noche y me acuesto temprano. Al otro día me fui tranquilamente al examen, cuando llegué, me dan ciertos nervios durante la explicación, pero después me tranquilizo. Lo sentí como un examen de lógica, todo me sonaba bien. En la parte de comprensión de lectura, las respuestas las encuentro bien... en la de analogías no le encuentro dificultad, ni a las matemáticas tampoco; cuando lo termino siento que me ha ido bien. Al salir y comparar respuestas, casi nadie tenía respuestas parecidas a mí, lo cual me preocupaba... Al día siguiente, encuentro que hay otras respuestas diferentes y esto se hace eterno, todos los días le preguntaba a la Orientadora por el resultado (Paola).

El día anterior cené con mis papás y me acosté temprano. "Estése tranquila", me decían mis papás, para que llegara a hacer el examen con calma y tranquilidad. Mi papá me dio algunas recomendaciones para realizarlo: si usted practica se embota; me dio confianza todo lo que mi papá me había dicho. Considero que la prueba de admisión está acorde con el tiempo. Es un buen indicador de excelencia a futuro (Diana).

Hice la práctica del examen, asistí a una visita corta y luego me acosté temprano. Para este examen no se puede estudiar... Cuando llegué a realizar el examen de la U, en la contraportada del folleto de práctica, 
comenzaron a firmar todos los compañeros de los quintos que estaban haciendo el examen. Me sentía tranquilo, siento que me desestresó la recaudación de firmas... El examen me cansó y sentí que era muy largo. Considero que la parte de comprensión de lectura fue la más difícil, no era una lectura común; si fallé en alguna parte, fue allí. Lo esperaba más fuerte, las analogías fáciles, matemáticas fácil. Duré todo el tiempo para entregarlo, no me sofoqué (Manuel).

La noche anterior al examen de admisión de la U.C.R., nos pusimos a repasar el folleto entre mi amiga y mi novio. En octavo año, yo lo había repasado, me gustaba hacerlo para ver cómo salía. En el colegio, la profesora de español nos da una serie de analogías. Nadie más nos da preparación para el examen de admisión. No estaba preocupada por el examen, me acosté temprano. Yo siempre sé que lo voy a ganar. Era un examen entretenido para mí...

Realizo el examen en el Liceo... me comentan que se había accidentado un compañero, no me afecta mucho. $\mathrm{Al}$ iniciar el examen, me pareció más difícil que el del Tecnológico. En la parte de las analogías y las matemáticas fueron fáciles; les di más detalle a la comprensión de lectura, lo hice con calma, tranquila, no me pareció difícil. Al salir del examen, no me preocupó éste, sino la noticia del accidente del compañero (Carolina).

El día sábado, cuando fui a hacer el examen, llevaba la actitud de siempre, hacer lo mejor, pero estaba tranquilo. Hice el examen despacio, de hecho fui el último en entregarlo, me pareció que estaba fácil (Marcos).

La Universidad, al promover un incentivo público a los primeros promedios de admisión, logra que el estudiante que obtiene el primero, segundo o tercer lugar, disfrute con su familia del reconocimiento a su esfuerzo académico, el cual se proyecta con mucha fuerza en sus compañeros de undécimo año y de todos los niveles, así como en el personal docente y administrativo y en los padres de familia.

En opinión de los informantes, en el colegio estos estudiantes se convierten en un símbolo de excelencia académica y en orgullo para la institución, especialmente si son de la zona rural.

Los informantes Marcos y Melissa narran las experiencias que compartieron con sus familias, el día que la Universidad les comunicó el logro obtenido en la P.A.A.:
Un día llegué a la casa donde vivía y me dijeron que me habían llamado de la Oficina de Registro de la U.C.R., y que querían hablar conmigo, que me llamaban más tarde. Me puse muy pensativo, no me imaginaba qué podía ser. Cuando llamaron y me comunicaron que estaba invitado a una Conferencia de Prensa, porque había obtenido uno de los mejores promedios de admisión, ¡no lo podía creer!

El día de la conferencia de prensa fue muy emocionante, me entrevistaron de Canal 7; fue curioso, porque la periodista de este canal fue la que me llevó donde don Ramiro Porras y le dijo: "A este muchacho le tienen que dar una Beca de Honor"; don Ramiro me dijo que quería hablar conmigo y que me citaba para el siguiente lunes a las 7 de la mañana, en su oficina.

Llamé al pueblo para avisar a mis papás, que fueran donde algún vecino a ver las noticias de las seis. Al otro día, mi foto fue la única que salió en La Nación; unos amigos me dijeron que habían escuchado mi nombre en Radio Reloj. ¡Todo era un gran sueño! (Marcos).

El día que me avisó la Universidad del resultado del examen, iba a estudiar con mi mejor amiga. El Sr. Ramiro Porras, Director del Registro de la U.C.R., me informó que había obtenido el tercer lugar del examen a nivel nacional; yo no lo creía; el Sr. Porras me dijo que tenía que ir a una conferencia de prensa... Escogí mi mejor blusa y mi mejor pantalón. Al llegar a la Universidad, nos dan un trato que nunca me habían dado en mi vida. Todos eran hombres, dieciocho de todos los promedios, nos hicieron esperar mientras llegaba la prensa.

Don Ramiro dice unas palabras y hay cámaras grandes y luces. Nos tomaron una foto con todos abrazados. Nos dieron todos los folletos y la felicitación, nos pasaron a un comedor y nos dieron un refrigerio. En mi casa, mi papá rompió a llorar, mis hermanas estaban felices... Al día siguiente, antes de hacer el examen de matemáticas, el profesor dijo que era un orgullo para el colegio, se le salía la alegría por todos los poros. Me mandaron tres telegramas de felicitación y me compraron flores en mi casa; amigos de mis hermanas y todo el mundo que me conocía me felicitaba. Yo me sentí muy orgullosa, porque soy de un colegio público y me sentía orgullosa de haber puesto a mi colegio en alto, era mejor que todos los colegios privados y yo estaba que no cabía en mí de la felicidad. El año 1990, fue un año especial, nos llamaron de la Casa Presidencial y me dijeron que por haber obtenido uno de los mejores promedios de admisión, nos iban a realizar un acto. El presidente Rafael Ángel nos saludó a mí y a mamá, nos entregaron en el acto un certificado de manos del presidente y todo el mundo aplaudió... sentí como un gran estímulo, estaban representantes en Deportes 
y todos los jóvenes que se destacaron ese año en un área; me sentía muy bien, todos representábamos lo mejor de todo; en ese momento pensaba estudiar Ingeniería Civil (Melissa).

Los informantes, en su totalidad, manifestaron que el logro académico más importante alcanzado en su vida estudiantil, fue el promedio de admisión obtenido en la P.A.A. de la Universidad de Costa Rica.

Les proporciona un alto nivel de satisfacción, que comparten plenamente con sus familiares y amigos y, además, éste se proyecta en el contexto sociocultural que los rodea. Esta vivencia la exponen los informantes Manuel y Paola.

Me comunicaron que tenía que presentarme a las 10 de la mañana, con uniforme, en la Oficina de Registro. Mis papás se emocionaron muchísimo... Nos recibe el Rector Luis Garita y representantes de la U, la prensa estaba convocada. Mi papá estaba muy contento; me entrevistó un periodista de Canal 2. Nos entrega el Rector un certificado por los Mejores Promedios de Admisión. Siento que cada día que pasa es un logro. El logro más grande que he obtenido en mi vida estudiantil y el más público, ha sido el Segundo Promedio de Admisión a la U.C.R. Mucha gente cree que a uno le va bien, solo porque se pasa estudiando todo el día.

Qué satisfacción para mis padres que no habían estudiado y que no me habían podido ayudar y que pudieran tener el ingreso de un hijo a la universidad, y que había salido adelante. En la casa no me han exigido nunca nada y esto les alegra mucho a ellos.

Se le fue la mano, me decía un compañero; yo nunca había esperado esto (Manuel).

El día que me comunica la U.C.R. el resultado del examen, estaba en la casa con mi mamá, estudiando para las pruebas de Bachillerato, recibí una llamada personal, me llamaba una muchacha de la Rectoría y me dijo: Señorita ... la llama la U.C.R., ya están los resultados de admisión y usted tiene el primer promedio. Yo contesté: está bien. Bajé las escaleras corriendo y se lo comuniqué a mi mamá, no lo creía, pensaron que era una broma y llamaron a mi tío y él confirma la noticia y me indica que tengo que presentarme a primera hora en conferencia de prensa. Me vestí corriendo y me presenté en la Rectoría con mi papá y mi tío; nos recibe el Vicerrector, tenían convocada a una conferencia de prensa. Me explican mi nota de admisión: 781. El Rector Don Luis Garita nos dirige unas palabras, él me preguntó que cuál creía que era el factor por haber obtenido el primer prome- dio, y yo le contesté: "La serenidad y la tranquilidad que uno tiene es esencial y el haber dormido mucho. La confianza que uno tiene en la realización del examen". Después de que la noticia fue conocida por familiares y amistades, me regalaron peluches, flores. En el colegio María Inmaculada me hicieron un mural, los profesores me regalaron tarjetas, libros; me hicieron llamadas telefónicas. También la Municipalidad de Coronado, me hicieron un acto y me entregaron un pergamino; la comunidad me hizo una misa y recibí muchas muestras de cariño (Paola).

En todos los informantes se manifiesta un deseo de superación personal, que los impulsa a realizar su mejor esfuerzo en pro de una meta. En su narración destacan momentos especiales que les ofrecen satisfacción personal y familiar, cuando alcanzan la meta con excelencia académica (en la escuela, en el colegio o en la universidad), así como cuando es meritorio su desempeño en el deporte, las artes o destacan sus capacidades en otras disciplinas. Así se reseña en las siguientes narraciones:

\section{Marcos:}

Obtiene el primer promedio en la P.P.A, con 781 puntos. Al ingresar a la U.C.R., Marcos enfrenta un período de desmotivación, debido al ambiente de la universidad y a la personalidad indiferente y distante de algunos profesores, lo cual repercute en sus notas de primero y segundo años.

Esta situación influye en que apruebe el primer y el segundo año, con notas que no son sobresalientes. En el tercer año, su actitud continúa igual en el primer semestre y empieza a preocuparse por sí mismo, por lo que acude en busca de apoyo con una profesora de confianza. Con ella establece una conversación fundamental para que se dé un cambio de actitud en él, en cuanto al ambiente universitario. Así lo expone el informante:

Pero, y los casi tres años de computación. ¿Qué significado había tenido ese tiempo? ¿Por qué esos años? Caminé hacia Compu, busqué a la profe..., mi mejor profesora, fuimos a su oficina y le conté mi historia. Ha sido la mejor clase de toda mi vida. Ella me 
planteó desde el principio, que lo más importante en la vida es sentirse feliz con uno mismo y con lo que uno hacía y que si eso implicaba abandonar proyectos, abandonar la escuela de Compu, entonces valía la pena, pero también me abrió nuevos panoramas; una visión que yo nunca había visto sobre mi carrera, me hizo ver cómo mi profesión también podía ser compatible con todos mis sueños y ambiciones. Las computadoras no eran solo máquinas para hacer programas tontos, era más que eso. Estaba en la carrera correcta, solamente que no lo sabía. Había vuelto a vivir. Ese semestre mi promedio ponderado fue de 9.25. El mejor de todos.

El cuarto año, fue mi mejor año. Empecé a amar mi carrera, mi escuela. Este año, por primera vez asistí a la Semana Universitaria. Comencé a salir con mis amigos, he hecho tantos amigos y tan especiales. Es increíble lo que la motivación puede hacer.

\section{Carolina:}

En el examen de admisión de la Universidad de Costa Rica logra el máximo puntaje, 800 puntos.

Carolina, para su ingreso a estudios superiores, tiene la opción de una beca en Munich, Alemania; la U.C.R. o el TEC. La elección de matricularse en la U.C.R. es personal, ya que su familia apoya la opción de la beca en Alemania. Así lo indica la informante:

El colegio me comunicó que me había otorgado la beca para estudiar en Alemania, me entregaron los papeles con los nombres de las carreras... Yo no estaba segura... Yo pasaba por la U y pensaba qué bonito estar en la U.C.R... Hablé con mis papás y yo les conté que sentía una presión por el estudio; no podía dilucidar lo que yo quería y uno debe de tratar de arreglar lo que uno quiere... Mi papá se sintió triste en el fondo y me dijo que hiciera lo que yo prefería. Todos en mi familia, a punto de becas se esforzaron y mi papá se sentía orgullosísimo de mí... yo pensaba, ¿cómo me voy a ir a estudiar a Alemania? Para mí, entrar a la U significaba algo que me daba más libertad, era algo más serio para mí.

$\mathrm{Al}$ ingresar al primer año de la U.C.R. se matricula en Estudios Generales:

$\mathrm{Al}$ ingresar a Generales, era como estar en el colegio, era un poco aburrido, es algo intermedio entre el colegio y la U... Estaba con tres compañeros, dos de ellos del colegio y el otro de Tibás, era bonito porque nos conocíamos, la profesora de Comunicación nos daba orientaciones de cómo tenían que ser las cosas... Nunca extrañé el colegio, lo que extrañaba eran los profesores.

Carolina indica que, en el primer año de estudios superiores, sus profesores en Estudios Generales tienen características diferentes, según su opinión:

Con respecto a los profesores, los de Generales tienen mucha conciencia social. La idea que tienen es profundizar en las materias. Los profesores son más cercanos, algunos son serios, accesibles y se interesan por uno, hay gente que no puede estar donde le gusta y eso es muy injusto. Hay gente brillante y no puede ingresar a la carrera que desean, quitan las oportunidades de ingreso.

La experiencia personal del ingreso a carrera denota en los informantes ilusión y entusiasmo por estudiar la carrera que seleccionaron, de acuerdo con sus intereses particulares; en muchos casos, desde que se encontraban en el colegio. Carolina narra así sus primeras vivencias:

Siempre me han gustado las ciencias, dije desde $\mathrm{V}^{\circ}$ año... Pensaba: ¿qué chiva trabajar en el campo! En junio hago la solicitud de ingreso a Agronomía. Ya que estaba empadronada en Química, mucha gente me criticaba por ingresar a una carrera tan fácil. Ingreso en 1995 a carrera... siento entusiasmo por ingresar a la Facultad de Agronomía, en la Escuela de Zootecnia. Ingreso a segundo año de carrera, en un grupo de tres mujeres y once hombres; matriculé cinco materias. Había gente de otros años, muchos reprobados o atrasados en el curso. Mis compañeras y yo estudiábamos y cumplíamos con los deberes de las materias, tratamos de establecer amistad con los compañeros...

Carolina propone las características que un profesor universitario debe tener para, además de impartir conocimientos, obtener el respeto de sus estudiantes:

El profesor debe saber muy bien de qué está hablando, para poder aclarar dudas; debe ser justo, que no tenga preferencias, que tenga orden para dar la materia... El profesor debe interesarse por el alumno; debe ser respetuoso del alumno, sin que sea frío, que tenga ética. Mi vida va a ser feliz, voy a estudiar y mis notas van a ser buenas. 


\section{Daniel:}

Logra el primer promedio de admisión de la U.C.R., con 780 puntos. De su ingreso al primer año de estudios superiores, Daniel describe sus experiencias en la Escuela de Estudios Generales:

Las clases de Generales y la buena relación con los compañeros me gustaba bastante... Sentía la presión de que la nota de admisión no era algo fortuito, que había obtenido esa nota y me sentía presionado de demostrar que sí podía dar más.

En Generales me entusiasmo más, eran profesores preocupados por los estudiantes... había gente del mismo nivel de uno, la relación fue buena, me llevé bien con la mayoría. El trato de los profesores era bastante cercano y el ambiente es agradable y no siento tanto el choque de pasarse del colegio a la universidad.

$\mathrm{Al}$ ingresar a la Universidad se siente solo en la Escuela de Derecho por no conocer absolutamente a nadie. Con los compañeros de Estudios Generales era diferente la relación, pues tuvo con quien relacionarse desde los primeros días.

Al iniciar sus estudios en la Facultad de Derecho la relación que establece con sus compañeros es distante, lo cual incide en su estado anímico y le ocasiona sentirse deprimido al finalizar el primer semestre. Así lo indica:

Con los compañeros de Derecho, era lo contrario a los de Estudios Generales, supongo que es consecuencia de ciertos prejuicios que uno pueda tener; tenía el concepto de que venían de otro círculo social y que yo no era de ese círculo; sentía que tenía que luchar más para poder surgir de entre esas personas, ya que ellos tienen mayores posibilidades que una persona de un nivel económico inferior.

La relación con ellos es ínfima. No puedo decir que no eran buenos alumnos, les iba bastante bien. Me sentía solo, por el hecho de no conocer a nadie... Al finalizar el primer semestre me sentía deprimido con el ambiente de la $\mathrm{U}$.

$\mathrm{Al}$ enfrentar esta situación, generada por el ambiente en Derecho, se siente solo, pero en ningún momento permite que esto le afecte en su rendimiento académico. $\mathrm{Su}$ promedio de notas es de 98 en el primer semestre y de 99 en el segundo semestre:

Me puse como meta, tener el mejor promedio de la Facultad y de la Universidad. Al concluir el segundo semestre, había tenido mejores notas de las que yo pudiera sacar. Quería demostrar que podía ser un buen estudiante en la carrera, no sé si podré ser un buen abogado.

En el curso de cinco años de estudios regulares en la Facultad de Derecho, Daniel tiene una serie de experiencias personales con profesores, estudiantes y con el entorno, que le permiten valorar las características del ambiente en general de esta Facultad.

\section{En su narración indica:}

Yo esperaba un ambiente rígido, el ambiente de la Facultad es de bastante competitividad, en algunos casos leal, en otros no. El afán de destacar se hace manifiesto... la posición de los compañeros es bastante superficial, ellos asumen diferentes posiciones, de acuerdo con los intereses que hay a su alrededor.

En el segundo año logra estudiar con mayor entusiasmo y se integra con dos compañeros en los trabajos grupales. Opina que, en relación con los profesores, en forma general son buenos, pero que se deben corregir los problemas que enfrenta la Facultad:

Lo que a uno le hace pensar en la carrera, son las contradicciones de criterio de los profesores... El profesorado es bueno en su nivel, pero se podría mejorar si hubiera interés del profesor hacia el alumno y de éste para el profesor. Para mejorar el rendimiento académico, se debe partir del control de los profesores... El Derecho no es una ciencia exacta, por lo tanto, es subjetiva la calificación; el criterio de evaluación es subjetivo en algunos profesores, y si uno ha puesto mucho empeño, causa frustración en el estudiante... Considero que se le debe dar seguimiento al estudiante, para que se conozca su adaptación a la Universidad.

Con respecto a su rendimiento académico, Daniel a pesar de sus problemas de salud, realiza en todas las etapas de estudio un gran esfuerzo y mantiene un 
rendimiento académico de 9,2 semestral, durante los cinco años de estudios superiores. Considera que el ambiente favorece que el estudiante se identifique con la Escuela:

Hay gente que se conforma con el mínimo para pasar la materia; yo obtuve un promedio de más de 90 al terminar el primer año de la carrera... me empecé a acomodar mejor y no sentía tanta soledad... Yo me identifiqué con las personas que son bastante críticas, preocupadas por ciertos problemas; es importante tener la oportunidad de conocer personas bastante cultas de la carrera... Mis compañeros estudian Derecho, porque quieren ser buenos abogados. Yo estudié leyes para contribuir con la sociedad... El estudio, es el mejor regalo que los padres le pueden dar a los hijos.

\section{Melissa:}

Obtiene el tercer promedio de la U.C.R., con 772 puntos. Al ingresar a la universidad se encontraba entusiasmada y quería ingresar a Ingeniería Civil; le agradaban la física y las matemáticas, pero sentía que no sentía seguridad para elegir la carrera. Así lo expone:

Realizo la matrícula en Estudios Generales y en las materias introductorias que sirvieran para varias carreras. Sentía que no tenía seguridad para elegir carrera. Estaba en el grupo 01, era bonito en parte, eran hiperactivos e hiperdespiertos. Extraño al colegio. Me gustaba la planta física de Generales, me gustaban los árboles... Los profesores de Generales, no tenían preferencias con los estudiantes; la de Filosofía trató de inculcar valores, la profesora de Historia solo nos inculcaba los valores del marxismo, algo nuevo para mí. No me costó demasiado adaptarme al ambiente de la U, ya que encontraba gente afín. En el colegio estudiaba con compañeros, al ingresar a la U, con mi cuaderno de apuntes me acostumbré a estudiar sola.

En el segundo año lleva materias para varias carreras, ya que todavía no estaba muy decidida; en el primer semestre obtiene promedio de 9,5 a 10. A mediados del segundo año decide ingresar a Derecho, pero no recibe orientación vocacional; su decisión la sustenta en el análisis del folleto de oportunidades educativas de la U.C.R.. Así lo plantea:
Yo siempre quise que mi carrera fuera para ayudar a los demás, pensaba... Voy a entrar a Derecho, voy a estudiar Derecho... yo quería defender a los pobres... a la parte débil del mundo.

Al ingresar a la Facultad de Derecho considera que enfrentó un ambiente superficial, debido al comportamiento de estudiantes y de algunos profesores. En su narración así lo expone:

Yo ingresé a Derecho y había mucho lenguaje que aprender. Mis compañeros sólo hablaban de sus casas, sus carros y de lo que tenían; yo no podía ponerme a hablar en igual forma... Me preguntaban de qué colegio venía y al contestar, rechazaban mi institución pública... En el primer año, me siento como un pez en el agua, el estudio era importante para todo el grupo, pero me afectaba muchísimo el ambiente, los compañeros son tremendamente superficiales. Yo creo que no saben que existen los pobres, son vacíos, fiesteros, ... Las personas que son humanas en realidad, me caben en los dedos de la mano... No encuentro a alguien que calce con mi forma de ser y eso me hacer estar sola.

Melissa considera que en el ambiente universitario hay profesores que orientan al estudiante y fortalecen su autoestima, pero hay otro grupo que lo desmotivan. Así lo manifiesta:

Estuve indecisa en el primer año, entre Derecho y Antropología, yo pensaba... Derecho para poder vivir, Antropología para poder vivir feliz. Busqué a un profesor de Sociología, y le plantee mi indecisión, él me dijo: "Dedícate a Derecho, es más seguro". Esto me ayudó, ya que me explicó su criterio con claridad... En mi primer curso de Filosofía, la profesora que lo impartió se acercó a los estudiantes, era muy sensible, era noble y dulce para tratarnos... En el segundo semestre del primer año de estudios en la U, matriculé varias materias, el profesor de cálculo que le dicen..., fue un impacto total, uno se quedaba viéndolo y se preguntaba: ¿qué es esto? Él tenía sus preferencias, desde el primer día nos mandaba a estudiar, fue difícil, nos daba un poco de tensión... creo que por ser profesores, no tienen derecho a tratarlo mal a uno.

Basada en sus vivencias de años de estudios universitarios, Melissa expone que lo que más valora en un profesor es:

... que conozca y maneje bien, no solo la materia que está dando, sino una cultura general. Que se esfuerce 
porque uno entienda, que muestre calidez hacia uno, que sepa el nombre, que lo trate a uno con respeto y que no tenga preferencias por los alumnos; que sea puntual y responsable... Un buen profesor, es una buena persona, el cariño que le tiene a la profesión se refleja... Un muchacho que está en la disyuntiva de salirse o no de la U, podría acercarse a un profesor y que éste le diera su apoyo. Para mí es una felicidad sacarme un 10; pero sacarme un 10 con un profesor fácil, no es igual que sacarme un 10 con un profesor difícil, pero bueno, que explique. Es mi mayor orgullo como estudiante.

\section{Manuel:}

En la P.A.A. de la Universidad de Costa Rica logra el segundo promedio de admisión, con 796 puntos.

Manuel siente nostalgia de terminar sus estudios en el colegio y preocupación por el ingreso a la universidad. Le agrada Química y empieza a obtener información sobre las carreras a partir del mes de enero; indaga en las Facultades. Al ingresar a Estudios Generales no conocía absolutamente a nadie. Le agradaba encontrarse con algún compañero del colegio. Considera que fue difícil ambientarse en la universidad, especialmente por tener pocos amigos. Así lo manifiesta:

Durante todo el primer año, especialmente el primer semestre, me siento mal en la Universidad, era muy diferente a lo que yo estaba acostumbrado,... no me da timidez cuando necesito hablar con la gente. Empecé a conocer muchas personas y poco a poco fue haciendo amigos. Me afectaba el tener pocos amigos. Apenas salía, quería irme para la casa y no porque estuviera extrañando la casa... viajaba cuatro horas diarias, para estudiar en la U.C.R.

En el primer semestre recibe información sobre carreras que se vinculan con las ciencias; recibe la descripción de la carrera de Tecnología de Alimentos, por parte de un representante de productos químicos para aves, quien le explica detalles del tipo de trabajo que se realiza. Esto despierta su interés y se dirige a la Escuela de Tecnología de Alimentos, en donde le indican que la carrera es interdisciplinaria, difícil y de grupos pequeños de admisión. Siente un poco de indecisión, pero en el segundo semestre decide el ingreso a esa carrera, según su criterio, porque abarca todos los campos, por lo cual se matricula en las materias que le sirven para el ingreso a la carrera:

Me sentía contento porque iba a carrera y dejaba de ser de la masa flotante de la U; tenía mucha confianza en entrar a la carrera... Me comunican de la Escuela, que había sido el primer promedio de ingreso a carrera, pero que me faltaba Matemáticas 325, la cual la había perdido en el segundo semestre, por el miedo que adquirí con el profesor que le dicen... yo no entendía nada. Así que matriculé todo el bloque de carrera, menos Matemáticas 425.

En el primer semestre de ingreso al II año de la carrera de Tecnología de Alimentos, siente diferencias con el ambiente en que se desenvuelven sus compañeros. Así lo indica:

Yo noté que éramos diferentes, la forma de mi vida era diferente a la de ellos; por ejemplo, ellos decían: vámonos a pasear a tal lado, hablaban de sus fiestas en las que tomaban licor y yo no estaba acostumbrado a eso.

Esta circunstancia no le afecta en su relación con los compañeros, pues participa, pero mantiene su criterio. Considera fundamental el apoyo de sus padres en esta etapa de estudio:

Mi papá me decía que estudiara sin presión... él está orgulloso de que esté en la Universidad y le gusta la carrera que estudio... Conservo mi beca 10, por las notas que obtengo, y mis padres me ayudan con la alimentación y el transporte... Mis papás confían mucho en lo que yo hago, tienen mucha seguridad en mí. Mi papá dice que ahorita me gradúo y los mantengo; ellos están muy ilusionados de que termine y me preguntan sobre cosas de la carrera... también mi hermano le gusta el estudio y tiene expectativas en torno a lo que va a estudiar.

En el tercer año de carrera, su promedio es de 9,00. Opina que, al ser la carrera interdisciplinaria y no disponer de edificio propio, los estudiantes enfrentan limitaciones que en alguna medida los afectan. De esa manera lo plantea: 
$\mathrm{Al}$ ser interdisciplinaria, nosotros somos los nómadas de la U, solo tenemos un aula y lo demás son oficinas administrativas... usamos la planta del C.I.T.A. (Centro de Investigación en Tecnología de Alimentos), para prácticas y laboratorios... Sería una gran inversión el tener edificio propio. Los traslados son de Tecnología de Alimentos a Ingeniería, Química; la relación con ellos es buena.

En los años de estudios en la U.C.R. ha recibido como incentivo la beca de estímulo que se otorga por el promedio de admisión. No conoce de ningún otro reconocimiento por el récord académico del estudiante. Así lo expone en su narración:

En la U, yo nunca he oído nada de ningún reconocimiento... yo creo que a mí me afecta, el que no se estimule al estudiante... Siento que uno es un número, un carné y nada más; esto da desilusión, sobre todo en los primeros años. Con solo que fuera a nivel de las Escuelas, sería importante el estímulo de la U, sería un factor importante, lo motivaría a uno para esforzarse más.

En cuanto a la relación con los profesores, Manuel considera que la mayoría de ellos son buenos, aunque cree que existen algunas excepciones con profesores que, con su comportamiento personal, desmotivan a los estudiantes. De esta manera lo refiere:

El único problema que enfrenté en el primer año de estudios, es en el curso de matemáticas, que no entendía... el profesor no explicaba, duraba toda la lección haciendo un ejemplo y tal vez no lo había terminado y decía: háganlo como quieran, la cosa es que pasen... Este curso me despedazó toda la seguridad en mí mismo, yo sentía que ya no la tenía, antes yo sentía que podía hacer todo... Antes me preocupaba que debía de sentir que todo estaba bien, si no, yo no entregaba un examen, a partir de allí no... La cosa era pasar este curso... Le decían... y fue mi pesadilla, yo lo veo y todavía siento escalofríos. Empecé a sentir miedo de los cursos, fueron como dos años así.

Manuel valora el estímulo que un profesor le da al estudiante, así como sus actitudes personales para con el estudiante. Es lo que a continuación refiere:

... el profesor debe ser exigente, rígido, pero es importante valorar el trato con el estudiante, el interés del profesor por cómo le va al estudiante, el que llegue a la hora de la clase... El año pasado una profesora estimuló mucho al grupo, para el cambio de promedio; desde el primer día llegó y dijo que no dejaran nada para última hora. Apenas entregó la primera nota, nos decía que uno vale y que uno puede. Lo alentaba a uno tanto, que era como lo que yo necesitaba, era como el cariño que le debe tener uno al estudio...

\section{Diana:}

Obtiene el tercer promedio de admisión en la U.C.R. con 773 puntos. Ingresa a la Escuela de Estudios Generales completo en la Universidad. Siente un alto grado de motivación por sus estudios universitarios:

... Me siento con mayor confianza de ingresar a la U, me sentía sumamente positiva. En Generales fue muy bueno, yo no quería encontrarme a nadie del ..., me sentía como libre de toda la presión del colegio, me sentía menos reprimida... Estuve en el Tribunal de Elecciones de Generales y tuve una participación activa en él...Fue un año genial, me fascinó la U y me sentía sumamente feliz.

En el transcurso del primer año de estudios en la universidad, Diana analiza su elección de carrera; descarta la opción de ingresar a Farmacia y decide su ingreso a la Escuela de Medicina:

Me motiva mucho el pensar en el ingreso a Medicina, yo sabía que con mi promedio estaba segura de que podía entrar. Tenía que matricular el bloque de Medicina, el Seminario de Realidad Nacional... fue un año muy duro, por la cantidad de materias.

En el ingreso a carrera matricula siete materias para el primer semestre. Considera que el ambiente de la Escuela de Medicina es frío y muy exigente.

En el segundo año siente que son demasiados los estudiantes matriculados (117), por lo que la relación de los profesores con los estudiantes es despersonalizada:

Mi horario en Medicina es de 7am a 5pm, tengo una hora para almorzar. El segundo año es de mucho desgaste, eran semanas de exámenes, con demasiada materia; a pesar de dedicarme solo a estudiar, el tiempo es insuficiente, uno tenía que esforzarse mucho. 
La Escuela de Medicina, es muy fría de parte de todos los profesores, el trato es despersonalizado. Yo sentía que en la carrera éramos un estorbo, somos demasiados... En el primer semestre éramos muchos, ingresamos al primer año 117 y en quinto año queda como el $40 \%$. En ningún momento he dudado de estudiar medicina, de querer seguir en los cursos. Sé que hay carreras más fáciles, pero no la cambiaría. Ese año, es pura fuerza mía.

Le corresponde recibir los cursos en el Hospital Calderón Guardia, donde considera que tiene experiencias significativas en cada semestre. Así lo indica:

En el tercer año de la carrera, voy para el Hospital Calderón Guardia; me dijeron: "Bueno, doctora, póngase la gabacha”. Me encantó la calidad de la gente, todo el mundo se lleva bien, las relaciones interpersonales son muy buenas, lo pude apreciar desde el inicio del primer semestre. En las mañanas iba a clases y en la tarde recibía Patología General y laboratorio, tenía dos rotaciones. Ese primer semestre obtuve notas muy buenas... Me atrae mucho el ambiente hospitalario, yo voy a tratar de ser humana con la gente, tratar de no caer en el mismo plano de lo que uno ve; hay tantas cosas que se deben cambiar... Al finalizar el primer semestre, tengo problemas de salud, empecé con crisis de ausencias y mareos, me caía, mis compañeros no me dejaban estar sola, tuve problemas respiratorios, fue medio crítico el asunto... fue debido a tanto estrés acumulado durante tantos años, estuve así tres meses. Mis papás no querían que matriculara el segundo semestre, yo no le encontraba sentido a quedarme sin estudiar; ingreso en agosto al segundo semestre con problemas de salud.

\section{Diana opina de la siguiente manera en cuanto a su vivencia universitaria:}

Caracterizo la etapa de la Universidad, como la mejor de mi vida; yo considero que soy una excelente estudiante, aunque no lleve notas de 10 , yo he dado el $100 \%$; creo que lo que se aprende ahora no hay tiempo de aprenderlo después... En mi familia me dieron mucho apoyo y muy fuerte; mi mamá, en los primeros años me sostuvo a pura oración. Nunca he tenido la intención de dejar la Universidad, llegué con la ilusión, con muchos ideales y deseos de ser un buen médico.

Diana considera que los profesores de la Escuela de Medicina son buenos, exigentes y distantes del estudiante. Así lo relata:

Era una gran cantidad de materia; no eran solo los exámenes, era pensar en otras prácticas, en el laboratorio, en la bibliografía médica. El Dr. ... es excelente, pero exige que uno sepa tanto como él, en los exámenes, la clase del día; él daba los temas más difíciles y ejercía mucha presión; yo lo he tratado de disfrutar... El profesor de Anatomía Topográfica, era como un libro y captaba mucho la atención de los estudiantes. Hacía dibujos con facilidad. No me quejo de las evaluaciones, las considero muy justas. En los laboratorios era estresante, cuando daban mucho material los profesores. El curso fue genial en Obstetricia y en Ginecología, lo disfruté muchísimo.

\section{Adrián:}

En la P.A.A. de la Universidad de Costa Rica obtiene el tercer promedio de admisión, con 764 puntos.

Adrián considera que en $\mathrm{V}$ año las carreras de Derecho, Economía, Medicina e Ingeniería Eléctrica le atraen para ingresar a la U.C.R. Al obtener el segundo promedio de admisión decide ingresar a la Escuela de Medicina. Esta decisión la comparte con alegría su familia.

Inicia los trámites de ingreso en el mes de enero. Así describe sus expectativas:

Sentía ansiedad del ingreso a la universidad; me preocupaba el hecho de viajar, el cambio de lugar, de personas... Me emocionaba conocer gente nueva. Me agradaba pensar que tengo admisión en Medicina...

Adrián considera que su elección de carrera es estable y durante el primer año de estudios no se modifica.

Ingresa a Medicina y se siente satisfecho de estar en la Universidad de Costa Rica. Le gustan los cursos de la carrera, aunque considera que el ambiente de la Escuela de Medicina es más rígido. Así lo expone:

Mi idea de estudiar Medicina es estable, me gustan los cursos de la carrera, hay muchísimo que aprender. El ambiente de Medicina, es más rígido. Hay personas que le ayudan a uno con el proceso de matrícula; con los estudiantes de segundo año, se hace una mayor identificación... Estudiar Medicina no es complicado, pero requiere mucho tiempo por parte del estudiante, la carga académica es muy fuerte. Implica un gran sacrificio personal. Se sale menos, el descanso entre semana es poco, se tiene menos horas de sueño... Yo me siento satisfecho y me gusta 
bastante. Me gusta pensar que va a ser una profesión dinámica, de ser minucioso y de tener cuidado... el hecho de enfrentarse a una situación y saber que uno va a realizar acciones y que esto va a ser en beneficio de la gente.

Adrián coincide con el resto de los estudiantes partícipes de esta investigación en que el profesor debe ser responsable, ordenado, que muestre interés por el estudiante y que sea seguro de sí mismo. También considera que debe motivar al estudiante y preparar bien la clase, lo cual ilustra de la siguiente manera:

Me gusta mucho Química, el profesor era bueno. En primer lugar, prepara una clase, hace práctica, no se guía sólo por el programa, da la materia bastante clara y se interesa por el grupo.

\section{Paola:}

En la P.A.A. de la Universidad de Costa Rica obtiene el primer promedio de admisión, con 781 puntos.

Paola recuerda que cuando revisa el plan de estudios de la carrera se entusiasma con la idea de ingresar a Medicina: "Lo que yo quería era que me fuera bien y mantener el promedio. Yo iba a dar lo mejor que pudiera".

En el primer año de la universidad percibe que la motivación y el esfuerzo del estudiante, son fundamentales para proseguir en el avance de los estudios superiores, según se aprecia en sus palabras:

En la U es la propia motivación la que le impulsa a uno a seguir. Los horarios son cansados, las materias duras, es poco el estímulo personal... En Estudios Generales no sentí rígida la relación con los profesores... las materias las considero importantes, dan cierta preparación y cierta guía, que son indispensables para continuar los estudios en la U...

$\mathrm{Al}$ referirse a sus experiencias en la vida universitaria, Paola manifiesta su satisfacción por sus logros en los estudios, así como también expone su criterio sobre los procesos administrativos:
Me gusta la Universidad. Me agrada el área de letras y de ciencias; para un crecimiento personal, me gustan más las letras; para el trabajo, las ciencias. Entre los aspectos positivos de la universidad, es que aquí la excelencia académica le cuesta al estudiante, existe cansancio; pero entre más le cueste a uno, más lo quiere... Los trámites administrativos para la matrícula, presentan problemas para el estudiante y esto causa desestímulo. No he sentido ningún tipo de estímulo para el ingreso a carrera... Yo creo en el estímulo que se da en el hogar; para mis papás todo es un acontecimiento de lo que me ocurre en mi carrera, mi familia y mi tía siempre preguntan por mí; esto motiva a que uno tiene que seguir adelante, yo siempre he sido el orgullo de mi familia, ellos dicen: "si yo estudio bastante, voy a ser como Paola”.

La opinión de Paola sobre la actitud de los profesores en el desempeño de sus funciones, coincide con el criterio de Diana y de Adrián (estudiantes de Medicina), en que la mayoría de los profesores de la Escuela de Medicina son rígidos, exigentes e impersonales en la relación con los estudiantes. Considera que la cantidad de trabajos y exámenes exige un gran esfuerzo personal por parte del estudiante y que esto influye en su rendimiento académico.

\section{Conclusiones}

En todos los informantes la constante de notas es excelente al concluir la educación diversificada y el bachillerato, debido al esfuerzo, dedicación y perseverancia en el estudio y en las altas expectativas que tienen de lograr el ingreso a la Universidad con las mejores notas.

El obtener el primero, el segundo o el tercer promedio en la prueba de aptitud académica de la Universidad de Costa Rica, es motivo de profunda satisfacción personal para ellos, lo cual es compartido por los miembros del núcleo familiar, pues lo proyecta en todo el contexto socioeducativo que los rodea.

El acto de reconocimiento público de los mejores promedios de admisión que ofrece la Universidad de Costa Rica, a los estudiantes, es de profundo significado en 
sus vidas. Sobre los incentivos que reciben los informantes, indican que fueron de la mayor relevancia en sus etapas de estudio, por lo que les resulta paradójico que, después de recibir beca de honor para ingresar a la Universidad por sus notas de admisión, el sistema universitario los convierta en un número de carné, no vuelven a ser considerados en ningún otro aspecto administrativo, docente o estudiantil. Es el esfuerzo y la motivación intrínseca de cada uno de ellos, lo que les permite continuar en un proceso de educación superior que consideran rígido. Los estudiantes manifiestan que algunos de los profesores de cada escuela, establecen una relación más cercana con las necesidades particulares de cada estudiante y aplican una valoración más acorde con su capacidad intelectual, aptitudes y habilidades.

El grupo de informantes percibe el ambiente de la Escuela de Estudios Generales como favorecedor en la integración del estudiante a la Universidad; existe un buen criterio sobre el interés de los profesores por sus alumnos y sobre la motivación que estos realizan para que continúen sus estudios superiores.

El ambiente de cada escuela o facultad es un factor determinante en el logro de las expectativas de formación profesional, en el que se destacan las relaciones interpersonales del estudiante con sus profesores y con los pequeños grupos de amigos, con los cuales comparten sus intereses y aptitudes.

Los informantes indican que, al obtener los primeros promedios de admisión, adquieren un compromiso de excelencia académica ante la familia, la Universidad y el contexto socioeducativo. Por ello se exigen a sí mismos metas elevadas en el rendimiento académico, en que la autoestima, la perseverancia, la competitividad y los fuertes intereses intelectuales son las características que destacan en su forma de enfrentar las circunstancias que se presentan en el ambiente universitario y que, en algunos casos, influyen en el rendimiento académico.

Todos los informantes se identifican plenamente con su papel y su responsabilidad de pertenecer a una carrera, y se sienten orgullosos de ser estudiantes de la Universidad de Costa Rica. Consideran la etapa de estudios universitarios como la mejor de sus vidas; en ninguna circunstancia han considerado la posibilidad de retirarse de la Universidad sin concluir su carrera.

Exponen su satisfacción por el papel de estudiante que desempeñan y por pertenecer a una facultad, independientemente de las eventualidades que enfrentan en el proceso de formación profesional.

Se considera esencial que el profesor universitario sea riguroso, exigente, puntual, responsable, especializado en su materia, con sentido humanitario, con un nivel profesional que lo acredite en su puesto y con una cultura general; que manifieste interés por el alumno y que lo incentive en sus expectativas profesionales; que respete el criterio con fundamento teórico del estudiante, que no discrimine las capacidades de éste en razón de su sexo o de su clase social; que valore la capacidad por encima de la media, demostrada en el excelente rendimiento académico, así como en las aptitudes y habilidades personales.

Es relevante para todos los informantes el ingreso a la Universidad de Costa Rica, con los mejores promedios de admisión, pues consideran que es el incentivo de mayor significado personal y familiar que se haya otorgado por sus logros de excelencia académica.

Los estudiantes participantes en la investigación, tienen una firme convicción de obtener las mejores notas desde que ingresan a la enseñanza primaria. En la universidad se esfuerzan por mantener el mejor promedio y aspiran a graduarse con las más altas calificaciones. Los estudiantes, al ingresar a la universidad, tienen definidas 
las opciones de carrera que desean estudiar; dedican tiempo completo a sus estudios universitarios; algunos complementan sus actividades con horas asistente, actividades en asociaciones de estudiantes o agrupaciones de jóvenes.

Prevalece en todos los estudiantes el esfuerzo, la constancia y un alto compromiso con sus responsabilidades y deberes en los estudios universitarios.

Expresan en su testimonio una satisfacción plena de realizar sus estudios superiores en la Universidad de Costa Rica; consideran que tienen identificación con su papel de estudiantes universitarios, con las exigencias y responsabilidades que demanda una carrera universitaria, por medio de la cual están definiendo su proyecto de vida.

En la investigación se establece que los estudiantes que ingresan con los primeros promedios de admisión, se esfuerzan por mantener una constante de notas que les permita conservar la beca de honor, que la Universidad de Costa Rica les otorga por su promedio de admisión, por lo que las notas que obtienen son superiores a 85 .

\section{Referencias bibliográficas}

Camacho, José A. La investigación cualitativa y sus aplicaciones. Apuntes para el curso Métodos de Investigación Cualitativa, mimeografiado. 1992.

Goetz, J.P. y LeCompte, M.D. Etnografía y diseño cualitativo en investigación educativa. Madrid, España: Ediciones Morata, S.A. 1988.

Martínez M., Miguel. La investigación cualitativa etnográfica en educación. Caracas, Venezuela: Editorial Texto S.R.L. 1991.

Taylor S.J. y Bogdan R. Introducción a los métodos cualitativos de investigación. La búsqueda de significados. Buenos Aires, Argentina: Editorial Paidós, Ibérica S.A. 1986.

Vivian María Pacheco Urbina. Profesora de la Escuela de Administración Educativa, Facultad de Educación, de la Universidad de Costa Rica. 